\title{
System of the Wind Wave Operational Forecast by the Black Sea Marine Forecast Center
}

\author{
Yu. B. Ratner, V. V. Fomin, A. M. Ivanchik*, M. V. Ivanchik \\ Marine Hydrophysical Institute, Russian Academy of Sciences, Sevastopol, Russian Federation \\ *e-mail: antonishka@gmail.com
}

System of the wind wave operational forecast in the Black Sea based on the SWAN (Simulating Waves Nearshore) numerical spectral model is represented. In the course of the system development the SWAN model was adapted to take into account the features of its operation at the Black Sea Marine Forecast Center.

The model input-output is agreed with the applied nomenclature and the data representation formats. The user interface for rapid access to simulation results was developed. The model adapted to wave forecast in the Black Sea in a quasi-operational mode, is validated for 2012-2015.

Validation of the calculation results was carried out for all five forecasting terms based on the analysis of two-dimensional graphs of the wave height distribution derived from the data of prognostic calculations and remote measurements obtained with the altimeter installed on the Jason-2 satellite. Calculation of the statistical characteristics of the deviations between the wave height prognostic values and the data of their measurements from the Jason-2 satellite, as well as a regression analysis of the relationship between the forecasted and measured wave heights was additionally carried out.

A comparison of the results obtained with the similar results reported in the works of other authors published in 2009-2016 showed their satisfactory compliance with each other.

The forecasts carried out by the authors for the Black Sea as well as those obtained for the other World Ocean regions show that the current level of numerical methods for sea wave forecasting is in full compliance with the requirements of specialists engaged in studying and modeling the state of the ocean and the atmosphere, as well as the experts using these results for solving applied problems.

Keywords: the Black Sea, SWAN, automatic system, wave forecast, altimetry, satellite measurements, wave height, validation, visualization, server.

DOI: 10.22449/1573-160X-2017-5-51-59

(C) 2017, Yu. B. Ratner, V. V. Fomin, A. M. Ivanchik*, M. V. Ivanchik

(C) 2017, Physical Oceanography

\section{Introduction}

From 2009 to 2014 Marine Hydrophysical Institute (MHI), as one of the seven marine forecast centers, participated in the European Union's FP-7 project $M y$ Ocean. Currently, the center continues to operate autonomously. One of the tasks of further improvement of the Black Sea Marine Forecast Center (BSMFC) operational system is related to the creation of integrated marine forecast systems based on simultaneous joint work of various forecasting models, including those intended for joint forecasting of the Black Sea circulation and waves.

Joint wave and circulation forecast will permit to increase the accuracy of calculations of sea current velocity, temperature and salinity in the upper sea layer and determine the sea wave characteristics. Improving the forecast quality is achieved due to a more correct consideration of the effects of the interaction of sea waves and currents using a complex prognostic model of these phenomena. 
In 2007-2008 as part of the BSMFC, the wave forecast system using the WAM model was in operation [1]. The wave forecast results were used to make the current velocity calculations in the Black Sea circulation model more accurate. Currently, it is possible to resume the solution of this urgent problem using the SWAN wave model [2, 3]. In 2009-2016 a number of papers [4-10], dealing with the wave forecast systems and results in the Black Sea basin, based on the use of the WaveWatch-III [11] and SWAN models, were published. The results of prognostic calculations for the Black Sea, obtained by the authors, as well as the calculations for other World Ocean regions [12] show that the current level of numerical methods for wave forecasting is in full compliance with the requirements of specialists engaged in studying and modeling the state of the ocean and the atmosphere, as well as the experts using these results for solving applied problems.

At the same time, some of the aforementioned systems operate in the research mode. Forecasts obtained through other systems operating online are difficult to adapt for sharing with models operating in the BSMFC. On that basis, the decision to develop the own system of forecasting sea waves was taken.

The present work is aimed to create and carry out preliminary validation of the sea wave forecast system functioning in BSMFC, for its subsequent integration with the Black Sea water circulation model. It will make it possible to increase the reliability of operational forecasts of water circulation and wave parameters.

In the course of the work, the following tasks were set:

1. Introduce the SWAN model into the BSMFC marine forecast system to provide its further joint application use with the Black Sea circulation model.

2. Create a user interface for the operational access of MHI staff and representatives of other interested scientific organizations to the wave forecast data.

3. Carry out a preliminary validation of the SWAN model, adapted for forecasts of the Black Sea waves in a quasi-operational mode for 2012-2015 and compare the results with similar work of other authors.

\section{BSMFC Wave Forecast System}

In BSMFC Wave Forecast System the SWAN model is used. It is based on the numerical solution of the wave energy balance equation in the spectral form [3]:

$$
\frac{\partial}{\partial t} N+\frac{\partial}{\partial x}\left(c_{x} N\right)+\frac{\partial}{\partial y}\left(c_{y} N\right)+\frac{\partial}{\partial \sigma}\left(c_{\sigma} N\right)+\frac{\partial}{\partial \theta}\left(c_{\theta} N\right)=\frac{S}{\sigma} .
$$

Here $N=E / \sigma$ is the wave action density; $E$ is the wave energy spectrum; $x, y, t$ are the spatial coordinates and time; $\sigma, \theta$ are the frequency and angular coordinates. Values $c_{x}, c_{y}, c_{\sigma}, c_{\theta}$ are the velocities of wave action density transport along the corresponding spatial and frequency-angular coordinates [13]. The source function on the right-hand side of equation (1) has the following:

$$
S=S_{i n}+S_{n l}+S_{w c}+S_{b f}+S_{d i b}
$$


where $S_{i n}$ is the source of wave generation by wind; $S_{n l}$ are the nonlinear interactions of spectral harmonics; $S_{w c}$ is the energy dissipation due to collapse of wave crests; $S_{b f}$ is the energy dissipation due to bottom friction; $S_{d i b}$ is the collapse of waves at critical depths.

The SWAN model version 42.10 applying OpenMP technology for multi-core processors was used. Wave characteristics were determined on $238 \times 132$ grid, covering the Black Sea with the step of $\sim 4.5 \mathrm{~km}$. The bottom topography was set on the same grid. The frequency interval $(0.05 \mathrm{~Hz} \leq \sigma \leq 1 \mathrm{~Hz})$ was covered by a non-uniform grid with 31 nodes. The model resolution along the angular coordinate was $10^{\circ}$. The time integration step in the equation (1) was 30 minutes. Bottom friction was determined on the basis of the Grant-Madsen theory [14]. At the entrance to the model, the wind speed was set at a standard height of $10 \mathrm{~m}$ with time discreteness of 3 hours.

The main output model characteristics are: height of significant waves, mean direction of wave propagation and mean wave period.

During the system development, the SWAN model was adapted to take into account the features of its functioning in the BSMFC. The representation of the Black Sea bathymetry data was improved and the input and output data of the model was harmonized with the nomenclature and presentation formats of the BSMFC data.

The automatic wave forecast system currently operates in an autonomous operational mode and performs a standard sequence of actions foreseen in making the forecasts - from planning the calculations to issuing the results of calculations of height, direction and period of significant waves on BSMFC servers. The atmospheric effect (wind speed) is set according to the data of the SKIRON Greek Atmospheric Forecast Center [15], regularly obtained by the BSMFC via Internet and prepared for application in the BSMFC models.

Functional diagram of the system is shown in Fig. 1. Its management is carried out using script files developed in the CalcmanPack language and executed by the interpreter programs of the CalcMan software package [16]. In the process of functioning, the system performs the following sequence of actions:

- forecast planning;

- standby mode to start the next forecast cycle;

- preparation of the input data necessary for the next cycle of the forecast;

- forecast of wave characteristics using the SWAN model;

- input and auxiliary data archiving, used and created during the execution of the next forecast cycle, in a local file archive on the BSMFC file server;

- preparation of output NetCDF-files of wave forecast, archiving of results in a local file archive;

- upload of the forecast results to THREDDS server to provide access to data for the users;

- work cycle completion, transition to the planning of the next cycle of calculations. 


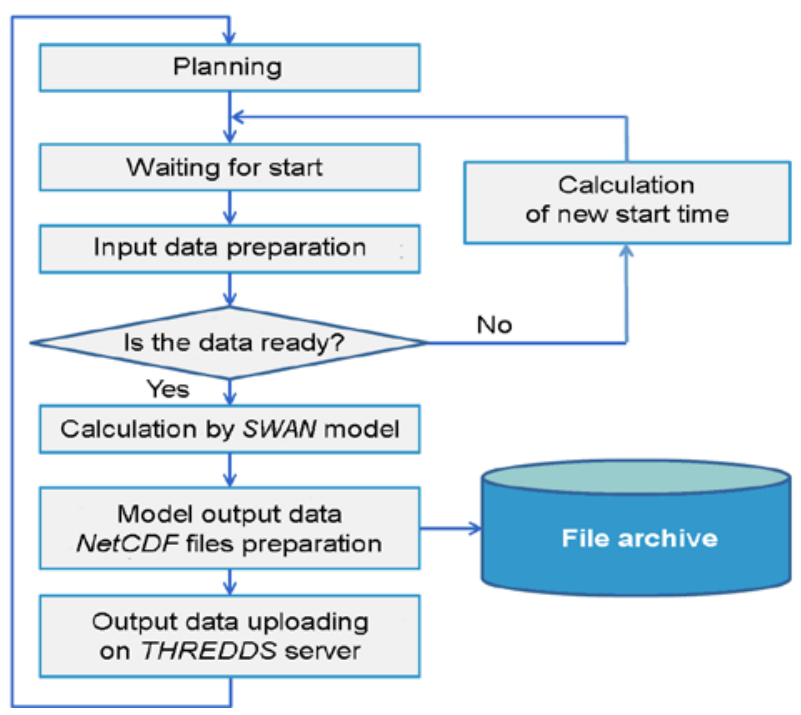

Fig. 1. Functional scheme of the BSMFC Wave Forecast System

When the system is running, operation logs are automatically created for each calculation cycle separately. They record the results of each step of the work and the problems that appear during the forecast execution. Operation logs are available via the Internet.

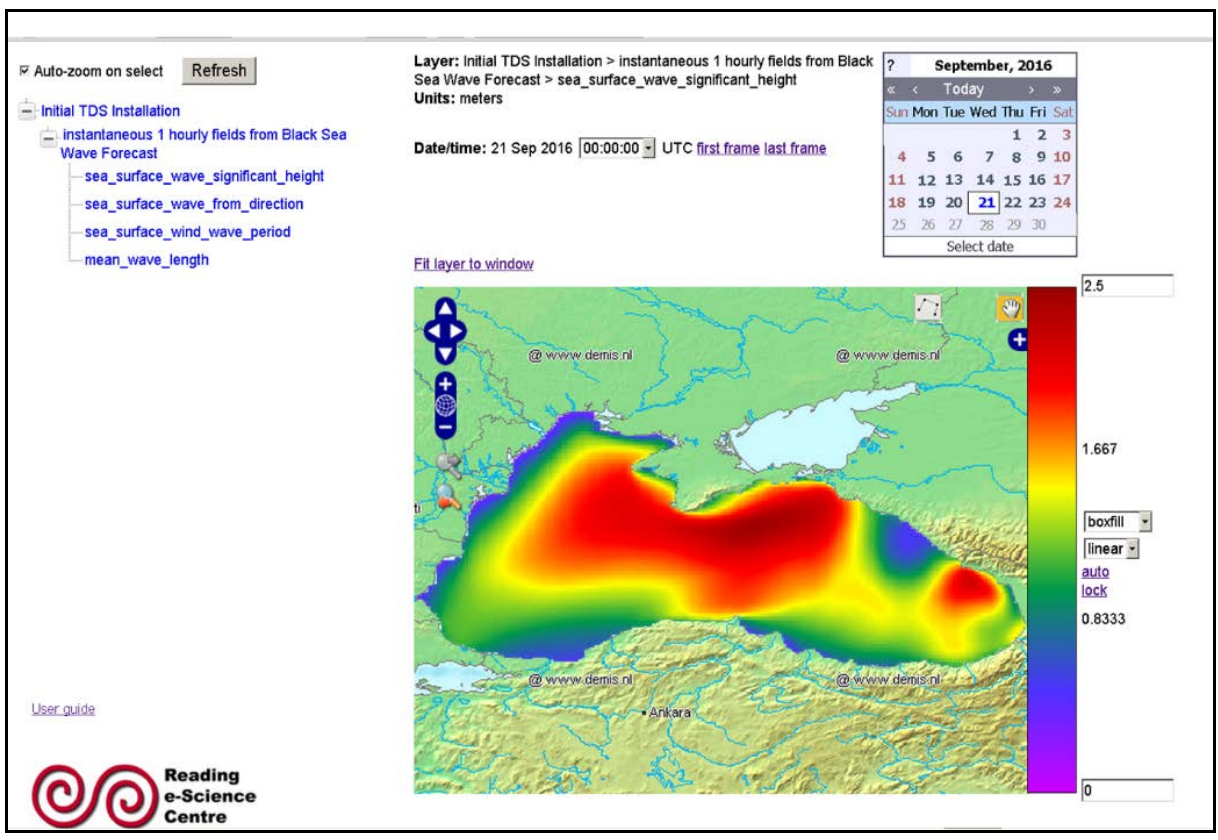

Fig. 2. Example of visualization of the field of heights of significant waves using the Godiva2 interface 
Access to data stored on THREDDS server is realized through the correspondding product lines $[17,18]$. A special NetcdfSubset interface is used to select and download data on the necessary parameters of the marine environment in an arbitrary part of the Black Sea water area [18]. Currently, for reasons of saving disk memory resources the data from the BSMFC file server can be downloaded for any period of time within 90 days before and 5 days after the current date.

Visualization of the wave forecast results is carried out via Godiva2 interactive interface - the standard component of THREDDS server [17]. It permits to obtain the value of the predicted parameter at any point in the water area, visualize horizontal and vertical sections, create animated images at specified time intervals and build time series at fixed points. An example of visualization of the wave forecast results is shown in Fig. 2.

Currently, the forecast system works in the operative mode.

\section{Validation of the results of the BSMFC wave forecasts}

To validate the prognostic calculations, GDR data archives (on wave heights) obtained by the Poseidon-3 altimeter of the Jason-2 satellite were used [19]. The model calculations data were linearly interpolated in space and time to the points and time of remote measurements. The number of joint data $N=63315$. The validation period for wave forecasts is from 2012 to 2015. According to the Jason-2 satellite product guide [19], the expected standard deviation for errors in recovering the height of significant waves is $0.25 \mathrm{~m}$, the actual value is $0.12 \mathrm{~m}$.

During the model validation the satellite data passed the standard filtration procedure described in the Jason-2 satellite product guide [19]. Some filter parameters given in this work have been changed in accordance with the materials described in [5]. To the standard procedure for satellite data filtering in [19], the supplementary filters used in [5] were added. In particular, the satellite data with a wave height of less than $0.1 \mathrm{~m}$ are proposed to be filtered in the present study proposes to filter. No own procedures for filtering satellite data were used by us.

The analysis of the forecast results was carried out on the basis of the scattering diagrams of the prognostic values of the heights of significant waves relative to their values obtained from the Poseidon-3 altimeter and the following statistical characteristics of the differences between the predicted and measured values:

$$
\begin{gathered}
M E=\frac{1}{N} \sum_{i=1}^{N} H_{m, i}-H_{s, i}, \quad S D=\sqrt{\frac{1}{N} \sum_{i=1}^{N}\left(H_{m, i}-H_{s, i}-M E\right)^{2}}, \\
R M S E=\sqrt{M E^{2}+S D^{2}}, \quad S I=\frac{R M S E}{M H_{s}}, \\
R=\frac{\sum_{i=1}^{N}\left(H_{m, i}-M H_{m}\right)\left(H_{s, i}-M H_{s}\right)}{\sqrt{\sum_{i=1}^{N}\left(H_{m, i}-M H_{m}\right)^{2}\left(H_{s, i}-M H_{s}\right)^{2}}}, \\
M H_{m}=\frac{1}{N} \sum_{i=1}^{N} H_{m, i}, \quad M H_{s}=\frac{1}{N} \sum_{i=1}^{N} H_{s, i},
\end{gathered}
$$


where $M E$ is the mean deviation; $S D$ is the standard deviation; RMSE is the root mean square deviation; SI is the scattering index (relative root mean square deviation); $R$ is the correlation coefficient; $M H_{m}$ and $M H_{s}$ are the mean wave heights calculated from forecast data and satellite measurements.

Fig. 3 shows joint empirical distributions of the wave heights obtained as a result of the forecast and measurements from the earth satellite for the forecast periods in the intervals $0-1,2-3$ and $4-5$ days. The whole range of values from 0 to $8 \mathrm{~m}$ is divided into $160 \times 160$ pixels (cells) with a size of $0.05 \times 0.05 \mathrm{~m}$. For each cell the number of pairs of calculated and measured values of the wave height that hit this pixel was calculated. The number of hits per pixel is shown in color. Correspondence of colors to the quantity of the pairs which have got in pixels is shown on a color palette on the right.
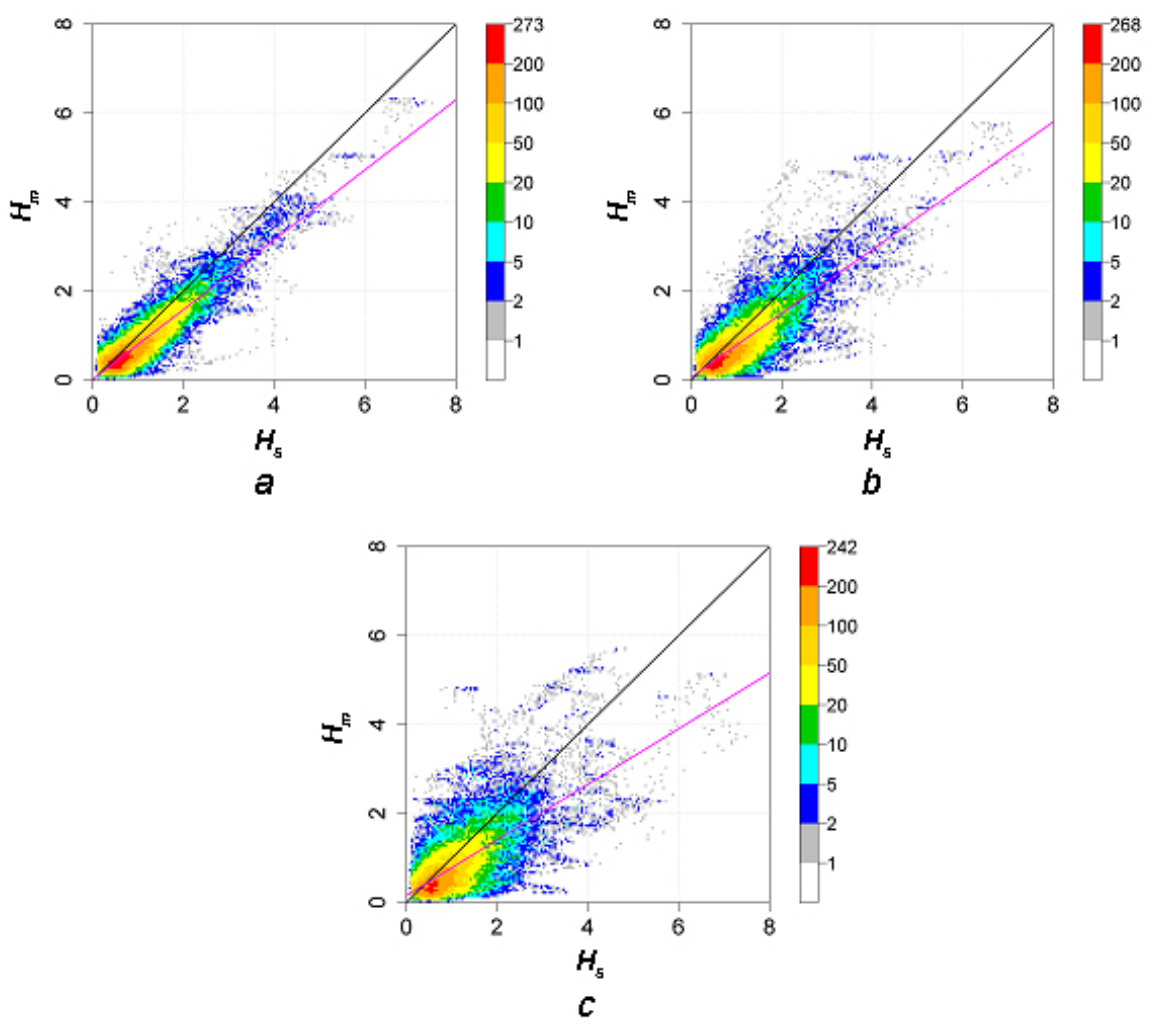

Fig. 3. Diagrams of scattering of prognostic values of the heights of significant waves with respect to the data of altimetric observations: $a$ - during the forecast for $0-1$ day; $b$ - during the forecast for $2-3$ days; $c$ - during the forecast for $4-5$ days

Tab. 1 shows values of the mean $(M E)$, standard $(S D)$ and root mean square (RMSE) deviations, scattering index $(S I)$ and correlation coefficient $(R)$, as well as the linear regression coefficients - the slope $(a)$ and displacement $(b)$ values of the prognostic wave heights on their measured values. 


\section{Statistical Characteristics of the Differences between the Prognostic and Measured Values of the Wind Wave Height in the Black Sea}

\begin{tabular}{c|c|c|c|c|c|c|c}
\hline $\begin{array}{c}\text { Period of } \\
\text { the } \\
\text { forecast }\end{array}$ & $M E$ & $S D$ & $R M S E$ & $S I$ & $R$ & $a$ & $b$ \\
\hline 0-1 days & -0.21 & 0.32 & 0.39 & 0.36 & 0.90 & 0.78 & 0.02 \\
2-3 days & -0.24 & 0.43 & 0.49 & 0.46 & 0.81 & 0.72 & 0.07 \\
4-5 days & -0.24 & 0.55 & 0.61 & 0.57 & 0.69 & 0.62 & 0.16 \\
\hline
\end{tabular}

The results obtained in the present study were compared with the data of [4-7]. In [4] the calculations were carried out for the period of 15.04-30.11.2011. To compare with the prognostic wave height values, the Jason1, Jason2 and Envisat satellite measurements were used. In [5] the calculations were carried out for the period of 01.10-31.12.2012. The Jason2 satellite measurements data was used. The results of the reanalysis of the significant wave heights obtained in [6] correspond to the period of 01.01-30.04.2002. When comparing the reanalysis results, the Topex satellite data was used. According to the data given in Tab. 7 [6, p. 14], the quality of the data from this satellite is the best. In [7] results of reanalysis of significant wave height values obtained within the period of 2010-2011 are presented. Comparison of these results with observational data was carried out using remote sensing of Envisat, Jason1 and Jason2 satellites in 2010-2011. Below, the data shown in Fig. 7, c [7, p. 8], obtained using the Jason2 satellite in 2010 is presented.

The results of comparing the present study estimates with the data of the listed works are presented in Tab. 2. They are given for the forecasts for a period of 0-1 day.

Table 2

Table of Comparison of Statistical Estimates from Tab. 1 with the Data of the Other Works [4-7]

\begin{tabular}{l|c|c|c|c|c|c|l}
\hline Source & $M E$ & $S D$ & $R M S E$ & $S I$ & $R$ & $a$ & \multicolumn{1}{c}{$b$} \\
\hline MHI & -0.21 & 0.32 & 0.39 & 0.36 & 0.90 & 0.78 & 0.02 \\
{$[4,8]$} & -0.09 & 0.32 & 0.33 & 0.28 & 0.91 & 0.92 & 0 \\
{$[6]$} & -0.01 & 0.36 & 0.36 & 0.36 & 0.78 & - & - \\
{$[7]$} & 0.03 & 0.40 & 0.40 & 0.44 & 0.85 & 0.84 & 0.11 \\
\hline
\end{tabular}

For prognostic periods from 0 to 1 day, the weakest dispersion of prognostic values relative to the measured values of wave height occurs. The correlation coefficient assumes a high value $R=0.9$. It is almost the same as in [5]. In other works, the correlation between calculation data and remote measurements is weaker. The standard deviation $S D$ takes values less than those calculated on the basis of data on the values of the mean and root mean square deviations given in [4-8]. Value of the mean error $M E$, obtained in the present study, turns out to be quite large. Its absolute value is about $60 \%$ of the standard deviation. For this PHYSICAL OCEANOGRAPHY ISS: 5 (2017) 
reason, the present estimates of the root mean square deviation and scattering index are higher than those in the works listed. Comparison of the slopes of the regression lines obtained here and estimated from Fig. 7, given in [5, p. 16], shows that the present estimate of the regression line slope is $14 \%$ less than that of [5].

With an increase in the forecast periods, there is deterioration in the correspondence between the distance measurement data and the calculated values of the wave height both in the present calculations and in the other works. Comparison of the forecasts obtained by in the present study for other forecast periods, with similar results of other authors, reveals the same features that occurred for the forecast for a period of 0 to 1 day.

\section{Conclusions}

1. The sea wave forecast system functions in an automatic operational mode. The created system works reliably. For the period from mid-June to mid-November 2016, there were no failures in the system related to the improper functioning of the developed software.

2. To maintain the system functioning, the following actions are compulsory: the daily monitoring of its operation results and elimination of problems occasionally arising from the lack of necessary input data, power outages and disruptions in the operation of internal and external data transmission networks.

3. The performed validation of the prognostic calculations showed good results in terms of the maximum correlation coefficient and minimum standard deviation. At the same time, according to the criterion of a systematic deviation minimum, the results obtained are inferior to the results reported in the other works.

Acknowledgements. The work was carried out within the framework of the State Order No. 0827-2014-0011 Research of the Regularities of Changes in the Condition of the Marine Environment on the Basis of Operational Observations and Data of the System of Diagnosis, Prognosis and Reanalysis of the Condition of Marine Areas (Operatio-nal Oceanography).

\section{REFERENCES}

1. Hasselmann, S., Hasselmann, K., Bauer, E., Janssen, P.A.E.M., Komen, G.J., Bertotti, L., Lionello, P., Guillaume, A., Cardone, V.C. and Greenwood, J.A., 1988. The WAM Model a Third Generation Ocean Wave Prediction Model. Journal of Physical Oceanography, [e-journal] 18(12), pp. 1775-1810. doi:10.1175/1520-0485(1988)018<1775:TWMTGO>2.0.CO;2

2. Booij, N., Ris, R.C. and Holthuijsen, L.H., 1999. A Third-Generation Wave Model for Coastal Regions: 1. Model Description and Validation. J. Geophys. Res., [e-journal] 104(C4), pp. 7649-7666. doi:10.1029/98JC02622

3. The SWAN team, 2016. SWAN Cycle III Version 41.10AB. Scientific and Technical Documentation. Delft: Delft University of Technology, Faculty of Civil Engineering and Geosciences, Environmental Fluid Mechanics Section, 138 p. Available at: http://swanmodel.sourceforge.net/download/zip/swantech.pdf [Accessed 10 May 2017].

4. Zelenko, A.A., Strukov, B.S., Resnyansky, Yu.D. and Martynov, S.L., 2014. Sistema Prognozirovaniya Vetrovogo Volneniya v Mirovom Okeane i Moryakh Rossii [A System of Wind Wave Forecasting in the World Ocean and Seas of Russia]. In: SOI, 2014. SOI Proceedings. Moscow, Obninsk: Artifex. No. 215, pp. 90-101 (in Russian). 
5. Dimitrova, M., Kortcheva, A. and Galabov, V., 2013. Validation of the Operational Wave Model WAVEWATCH III against Altimetry Data from JASON-2 Satellite. Bulgarian Journal of Meteorology and Hydrology, 18(1-2), pp. 4-17.

6. Rusu, L., Bernardino, M. and Guedes Soares, C., 2014. Wind and Wave Modeling in the Black Sea. Journal of Operational Oceanography, 7(1), pp. 5-20. doi:10.1080/1755876X.2014.11020149

7. Myslenkov, S. and Chernyshova, A., 2016. Comparing Wave Heights Simulated in the Black Sea by the SWAN Model with Satellite Data and Direct Wave Measurements. Russian Journal of Earth Sciences, [e-journal] 16(ES5002), pp. 1-12. doi:10.2205/2016ES000579

8. Strukov, B.S., Zelenko, A.A., Resnyanskiy, Yu.D. and Martynov, S.L., 2013. Sistema Prognozirovaniya Kharakteristik Vetrovogo Volneniya i Rezul'taty Ee Ispytaniy dlya Akvatoriy Azovskogo, Chernogo i Kaspiyskogo Morey [Forecast System for the Characteristics of Wind Waves and the Results of Its Tests for the Water Areas of the Azov, Black and Caspian Seas]. In: A.A. Alekseeva, ed., 2013. Informatsionnyy Sbornik № 40. Novye Tekhnologii, Modeli $i$ Metody Gidrometeorologicheskikh Prognozov i Rezul'taty Ikh Operativnykh Ispytaniy [New Technologies, Models and Methods of Hydrometeorological Forecasts and Results of Their Operational Tests]. Moscow, Obninsk: IG-SOTZIN, pp. 64-79. Available at: http://method.meteorf.ru/publ/sb/sb40/sb40.pdf [Accessed 10 May 2017] (in Russian).

9. Myslenkov, S.S., Shestakova, A.A. and Toropov, P.A., 2016. Numerical Simulation of Storm Waves near the Northeastern Coast of the Black Sea. Russian Meteorology and Hydrology, [e-journal] 41(10), pp. 706-713. doi:10.3103/S106837391610006X

10. Stoliarova, E.V. and Myslenkov, S.A., 2015. Prognoz Vetrovogo Volneniya Vysokogo Prostranstvennogo Razresheniya v Kerchenskom Prolive [High Resolution Wave Forecast System in Kerch Strait]. In: E.S. Nesterov, ed., 2015. Proceedings of Hydrometcentre of Russia. Moscow: Triada Ltd. Vol.354, pp. 24-35. Available at: http://method.meteorf.ru/publ/tr/tr354/tr354.pdf [Accessed 10 May 2017] (in Russian).

11. Tolman, H.L., 1990. A Third-Generation Model for Wind Waves on Slowly Varying, Unsteady and Inhomogeneous Depths and Currents. Journal of Physical Oceanography, [e-journal] 21, pp. 782-797. doi:10.1175/1520-0485(1991)021<0782:ATGMFW>2.0.CO;2

12. Zieger, S., Vinoth, J. and Young, I.R., 2009. Joint Calibration of Multiplatform Altimeter Measurements of Wind Speed and Wave Height over the Past 20 Years. Journal of Atmospheric and Oceanic Technology, [e-journal] 26, pp. 2549-2564. doi:10.1175/2009JTECHA1303.1

13. Holthuijsen, L.H., 2007. Waves in Oceanic and Coastal Waters. Cambridge: Cambridge University Press, 404 p. doi:10.2277/0521860288

14. Grant, W.D. and Madsen, O.S., 1979. Combined Wave and Current Interaction with a Rough Bottom. J. Geophys. Res., [e-journal] 84(C4), pp. 1797-1808. doi:10.1029/JC084iC04p01797

15. Papadopoulos, A., Katsafados, P., Kallos, G. and Nickovic, S., 2002. The Weather Forecasting System for Poseidon - an Overview. The Global Atmosphere and Ocean System, [e-journal] 8(2-3), pp. 219-237. doi:10.1080/1023673029000003543

16. Ivanchik, A.M., 2014. Upravlenie Funktsionirovaniem Avtomatizirovannykh Sistem Morskogo Prognoza [Controlling the Operation of Automated Marine Forecast Systems]. In: ISS, 2014. Sovremennye Problemy Gumanitarnykh i Estestvennykh Nauk: Materialy XX Mezhdunarodnoy Nauchno-Prakticheskoy Konferentsii 2-3 Oktyabrya 2014 g. [Contemporary Problems of Humanities and Natural Sciences: Procs of the $20^{\text {th }}$ International Scientific and Practical Conference 2-3 October 2014]. Moscow: Institute for Strategic Studies, pp. 56-61 (in Russian).

17. Korotaev, G.K., Ratner, Y.B., Ivanchik, M.V., Kholod, A.L. and Ivanchik, A.M., 2016. Operational System for Diagnosis and Forecast of Hydrophysical Characteristics of the Black Sea. Izvestiya. Atmospheric and Oceanic Physics, [e-journal] 52(5), pp. 542-549. doi:10.1134/S0001433816050078

18. MGI, 2017. THREDDS Data Server [Version 4.3.20 - 20131125.1409] Documentation. [online] Available at: http://mis.bsmfc.net:8080/thredds/catalog.html [Accessed 10 May 2017].

19. Dumont, J.P., Rosmorduc, V., Carrere, L., Picot, N., Bronner, E., Couhert, A., Desai, S., Bonekamp, H., Scharroo, R. and Leuliette, E., 2017. OSTM/Jason-2 Products Handbook. Washington, DS: NOAA/NESDIS. Polar Series/OSTM J400, Issue: 1 rev. 11, 77 p. 